\title{
La política multilateral de Chile en Asia-Pacífico ${ }^{1}$
}

\author{
Manfred Wilhelmy \\ Rosa María Lazo
}

A partir de la incorporación de Chile a APEC, se han abierto grandes oportunidades para la expansión de sus relaciones económicas internacionales en el Asia-Pacifico. La participación en este organismo representa una experiencia diplomática nueva que se apoya en el principio de regionalismo abierto dentro del cual el pais se inscribe. Partiendo de esta base, se examinan la formulación de la política multilateral de Chile en los foros económicos de la región, la situación de la política nacional en cada uno de ellos y los escenarios de evolución probables del posicionamiento chileno.

\section{Introducción.}

La incorporación de Chile a APEC en noviembre de 1994 abrió una nueva etapa en la participación nacional en los acuerdos regionales de liberalización económica, al insertar al país en el esquema de cooperación económica de mayor cobertura geográfica en todo el mundo, correspondiente, por otra parte, precisamente a las economias de desarrollo contemporáneo más dinámico en el sistema internacional, con insospechadas proyecciones hacia el siglo XXI, que reiteradamente ha sido caracterizado como el siglo del Pacifico. ${ }^{2}$ Este trascendental paso

\footnotetext{
${ }^{1}$ Escrito en el marco del proyecto FONDECYT N ${ }^{\circ} 1950834$, Relaciones contemporáneas de Chile con el Sudeste asiático.

2 Ver, entre otras obras, Frank Gibney, Pacific Century-America and Asia in a Changing World. (Nueva York: Charles Scribners Sons, 1992); Richard P. Cronin, Japan, the United States, and Prospects for the Asia-Pacific Century, (Nueva York y Singapur: ISEAS-St. Martins Press, 1992); Staffan B. Linder, The Pacific Century-Economic and political Consequences of Asian-Pacific Dymamism, (Stanford: Stanford University Press, 1986); y Lau Teik Soon y Leo Suryadinata (cds.), Moving into the Pacific Century: The Changing Regional Order in the Asia-Pacific, (Singapur: Heinemann Asia, 1986). En esta literatura, el libro de Gibney es la mejor obra de consulta general, mientras el de Linder se aproxima al concepto de regionalismo abierto y adelanta tesis que se popularizarian en los artos 90 .
} 
-que fue el desenlace de una intensa campaña diplomática desarrollada en los años anteriores, la que ha sido estudiada en detalle en el marco de este proyecto ${ }^{3}$ abre grandes oportunidades para la continuada expansión de las relaciones económicas internacionales chilenas en el ámbito de Asia-Pacífico, tanto en el plano comercial como el de las inversiones en ambas direcciones.

En este estudio nos interesa especialmente destacar las interrelaciones entre la política exterior y los foros del Pacifico. APEC representa un esquema de asociación regional inédito en la trayectoria de las relaciones internacionales y de la política exterior de Chile. Junto a las nuevas experiencias diplomáticas en Asia-Pacífico y a la incursión empresarial y de organismos oficiales, como ProChile, en nuevos mercados, este es uno de los aspectos más innovadores de las relaciones exteriores chilenas en el Pacífico. En efecto, el Foro de Cooperación Económica Asia-Pacífico se aparta significativamente de los cánones habituales de los acuerdos internacionales en que ha participado Chile, en la medida que no constituye un acuerdo multilateral expresado en un tratado internacional, ni tiene una institucionälidad preestablecida. Opera más bien como un sistema evolutivo de diplomacia económica multilateral basado en los consensos entre los Estados (economías) participantes, los que dialogan en torno a una creciente agenda de interés común, la que anualmente confluye en las reuniones ministeriales y -desde 1993-en las Cumbres de Líderes Económicos. Estas citas son los eventos en los que culminan los ciclos politico-económicos de debate y negociación en pos de las metas de liberalización y facilitación del comercio y las inversiones, así como de cooperación para el desarrollo entre las economías más avanzadas y otras economías de la región.

A diferencia de las organizaciones multilaterales de corte tradicional, caracterizadas por la institucionalización de las deliberaciones y los acuerdos, en APEC se está desarrollando básicamente un mecanismo de concertación de voluntades que se traduciría en acciones unilaterales de liberalización y, en general, de apertura económica por parte de las respectivas autoridades económicas. Ciertos intentos de los miembros anglosajones de APEC (Estados Unidos, Canadá, Australia y Nueva Zelandia) para reorientar APEC hacia la adopción de açuerdos multilaterales de estilo tradicional han sido exitosamente resistidos por los países del Este de Asia.

\footnotetext{
${ }^{3}$ Nos referimos al trabajo de Chantal Signorio "Chile y su Ingreso a APEC", Tesis de Magister, Santiago, Pontificia Universidad Católica de Chile, Instituto de Ciencia Política, 1996.
} 
Si bien en términos de la tradición jurídica y formalista de la política multilateral chilena cabría pensar en una coincidencia de puntos de vista con la orientación anglosajona, en la práctica la diplomacia.nacional ha procurado asimilar el estilo asiático de la cooperación voluntaria a través de la elaboración de consensos progresivos en la agenda multilateral. Nuestra hipótesis es que este ejercicio constituye una experiencia de aprendizaje de la diplomacia chilena, la que se apoya:en $n_{i}$ la percepción de la conveniencia de mantener el apoyo de los socios asiáticos de APEC que hicieron posible el ingreso de Chile al foro del Pacífico: Por otra parte, cabría asimismo plantear que hay un cierto paralelo entre el estilo político de la transición chilena, fundada en la política de los acuerdos, y lo que hemos descrito como la búsqueda de consensos al interior de APEC. Para la administración del Presidente Aylwin este paralelo no resultaba evidente porque Chile todavía no tenía experiencia práctica de participación en APEC: Bajo el actual gobierno, en cambio, se procura adaptar la política chilena en APEC al estilo asiático percibido como predominante en este foro, evitando, por otra parte, exponer esta política a los vaivenes de la contingencia interna, dándole de este modo el carácter de una tarea nacional de carácter suprapartidista (o, al menos, extrapartidista).

En términos de las observaciones precedentes, se advierte en la política multilateral chilena en el Pacífico un cierto carácter tentativo, ya que los actores van definiendo progresivamente y de manera un tanto intuitiva los caminos diplomáticos y las líneas dé política exterior económica a seguir. En la medida que las redes multilaterales del Pacífico se encuentran en plena evolución, esta política constituye una respuesta racional frente al contexto que se enfrenta. Asimismo, advertimos en la política nacional un räsgo que podríamos denominar preventivo, en la medida que mientras estuvo en duda el resultado de la Ronda Uruguay, el multilateralismo de APEC aparecía como una vía apta para evitar el riesgo de enclaustramiento de Chile en un eventual bloque económico-comercial de las Áméricas. Este elemento, desde luego, varió tras la conclusión de la Ronda y la constitución de la Organización Mundial de Comercio, ya que en adelante se veria a APEC como un factor impulsor del cumplimiento de los acuerdos de aquélla y aún de una futura profundización de la liberalización comercial global. Para la mantención de esta opción, resulta particularmente gravitante en la política chilena el concepto de regionalismo abierto como un proceso multilateral de apertura sin discriminación contra las economías que no 
forman parte de APEC. Por cierto, esta compatibilidad (e incluso sinergia) entre la política regional del. Pacífico y las tendencias y propuestas globales de liberalización constituye un motivo especial del interés chileno en el esquema de APEC y los demás foros que preconizan el regionalismo abierto.

Otra característica de esta política, que veremos más adelante, dice relación con la orientación simultánea y complementaria a diversos foros de la región (APEC, PECC y PBEC, a pesar del carácter de foro privado de este último). En este sentido, cabría decir que la política chilena promueve un mismo conjunto de intereses y objetivos a través de diferentes vías del multilateralismo del Pacífico. Por último, observamos una aproximación convergente multilateral y bilateral en el Pacífico: la política multilateral dependió directamente del desarrollo de relaciones bilaterales que permitieron forjar alianzas para el ingreso a APEC y la legitimación del papel chileno en este foro; por otra parte; uno de los beneficios esperados de la política multilateral es facilitar la profundización de los acercamientos bilaterales de mayor interés político y económico.

\section{El marco de acción política.}

El contexto de la participación chilena en la política multilateral del Pacífico se caracteriza, en lo interno, por la existencia de un apoyo creciente de un reducido pero importante grupo de agentes económicos nacionales, tanto empresariales como gremiales. Este apoyo ha sido impulsado por la percepción de los éxitos económicos del Asia-Pacífico así como por el crecimiento del intercambio chileno con el área. ${ }^{4} \mathrm{El}$ mismo se conjuga con la disposición de las autoridades políticas a reconocer la importancia de este nuevo eje de inserción internacional en la agenda de la política exterior, y se ha manifestado reiteradamente a través de la participación conjunta del sector privado y el sector público en las giras presidenciales y ministeriales al Este de Asia, lo que constituye, por otra parte, una señal dirigida a los asiáticos en el sentido que Chile actúa en el Pacifico como un país cohesionado.

Ello ocurre, sin embargo, en un marco deficitario de información acerca de los actores de Asia-Pacífico, más allá de reducidos círculos de

\footnotetext{
${ }^{4}$ Ver Manfred Wilhelmy y Carios Portales, Las Economias de Asia-Pacifico: Desarrollo Económico, Comercio Internacional e Inversión Extranjera, (Santiago: Fundación Chilena del Pacífico, 1995) y versión revisada y actualizada (con Ximena Clark), 1997.
} 
empresarios y de funcionarios del gobierno, y de la comprobación reiterada que la interacción sostenida con estos actores y el avance hacia resultados concretos, tanto económicos como políticos, exige asignar recursos significativos de tiempo, de acopio de información y análisis, así como de presupuesto para hacer viable en la práctica esta nueva línea de la diplomacia económica (e inevitablemente política) del país. En este aspecto queda de manifiesto que existe una vasta tarea por realizar con el concurso de todos los sectores interesados. Ello es válido tanto para el ámbito de APEC como para los otros dos circuitos relevantes del Pacífico, PECC y PBEC, a los que nos referiremos más adelante.

En lo externo, el contexto de la nueva diplomacia se caracteriza por grandes cambios políticos y económicos en el Este de Asia. Los primeros son examinados en otro trabajo ${ }^{5}$, mientras en el presente abordaremos algunos aspectos de los segundos. Bajo el gobierno militar, estos cambios se encontraban en una fase primaria, aunque ya fueron identificados por algunos de los principales actores, como el Canciller Hernán Cubillos a fines de los años 70, y su percepción estimuló el interés en el acercamiento nacional al Este de Asia. Ello se conjugó con una visión geopolítica de Chile en la Cuenca del Pacífico alimentada por la frecuente invocación (en alguna medida real, en parte mítica) de la navegación y el comercio chilenos en la Oceanía del siglo XIX. Al mismo tiempo, contribuyó poderosamente a la motivación de desarrollo de la política en el Pacífico la insatisfacción con el precario estado de las relaciones políticas con los países occidentales, críticos permanentes del régimen militar no sólo por problemas de derechos humanos, sino por sus caracteristicas autoritarias. Aparentemente, el liderato político, que venía experimentando el desgaste proveniente de este tipo de cuestionamiento, pensó que sería posible encontrar en el Sudeste de Asia y en otras subregiones de la Cuenca del Pacífico, nuevos espacios de maniobra para la política exterior que-se encontrarían libres de censuras de carácter político-deológico. Esta percepción estimuló de manera importante el interés del gobierno militar en los foros multilaterales del Pacífico, donde se pensaba encontrar ambientes propicios para el cultivo de las relaciones con los asiáticos. ${ }^{6}$

El gobierno del Presidente Aylwin naturalmente adoptaría una óptica diferente, dentro de su perspectiva de reinserción internacional de Chile.

\footnotetext{
${ }^{5}$ Manfred Wilhelmy y Rosa Maria Lazo, "El nuevo marco poltico-estratégico en el Este de Asia", manuscrito inédito.

${ }^{6}$ Ver Heraldo Munoz, Las Relaciones Exterlores del Gobierno Militar Chileno, (Santiago: Ediciones del Ornitorrinco, 1986).
} 
El Asia-Pacífico no fue una prioridad alta en el primer año de la nueva administración, en la medida que el gobierno estaba empeñado ante todo en la recomposición de los vínculos con Europa Occidental, Estados Unidos y América Latina. No obstante, muy pronto se impondría con fuerza la evidencia del dinamismo económico asiático, una percepción que contribuiría a cambiar las prioridades y conduciría al Este de Asia a integrarse con las otras áreas mencionadas dentro del cuadro general de las relaciones exteriores chilenas. Ello no quiere decir, sin embargo, que se haya tratado de un giro sistemático y cuidadosamente planificado a la luz de un policy review global y regional. Aunque el creciente peso e importancia de Asia-Pacífico resultara evidente para los actores chilenos, la lectura de la situación político-conómica global y sus implicaciones regionales revelaba factores de incertidumbre y de riesgo.

Mientras no se encontraba asegurado el éxito de la Ronda Uruguay, una fuerza importante en el mundo desarrollado apuntaba hacia la conformación de bloques regionales de carácter discriminatorio, potencialmente perjudiciales para una economía pequeña como la chilena. En este contexto, parecia agotarse la utilidad de la estrategia de apertura unilateral, y surgía con fuerza el imperativo de lograr acuerdos comerciales con los bloques. De hecho, la política de conciliación de múltiples acuerdos de libre comercio con la inserción en Asia-Pacífico, y especificamente APEC, bajo el signo del regionalismo abierto, se fue plasmando en forma gradual y en cierto modo tentativa. La dificil tarea de definir más específicamente los términos de la participación chilena en APEC corresponde al actual gobierno. ${ }^{7}$

En síntesis, el giro de la política exterior chilena hacia el Este de Asia representó un cambio importante, sin precedentes en América Latina, ya que se apartó tanto del tradicional énfasis de los países de la región en las relaciones con los Estados Unidos, buscando complementar las relaciones con Washington con un nuevo eje de acción internacional, como del tercermundismo ortodoxo de la centroizquierda latinoamericana, tradicionalmente mucho más interesada en el no alineamiento y en los frentes Norte-Sur de estilo reivindicacionista que en los nuevos esquemas multilaterales como APEC. Aún cuando el gobierno de la Concertación tuvo alguna participación - no central en su política exterior- en los no alineados, y siguió interesado en la coordinación político-conómica de los países en desarrollo, en la práctica

\footnotetext{
${ }^{7}$ Manfred Witheimy y María Teresa Infante, "La politica exterior del gobierno del Presidente Aylwin: una evaluación y algunas proyecciones", Estudios Sociales, N075, 1993, pp. 97-112.
} 
logró conciliar estos aspectos con su interés en el multilateralismo de Asia-Pacífico, a través de Indonesia en el caso de los no alineados y de Malasia como miembro del Grupo de los $15^{8}$

En los siguientes párrafos analizaremos los elementos multilaterales de esta política y nos referiremos a los actores que intervienen en ella, dejando para otro trabajo el estudio de las políticas bilaterales.

\section{Los cambios en el Este de Asia.}

El internacionalista malasio Noordin Sopiee ha caracterizado la transformación contemporánea del Este de Asia como una revolución que es al mismo tiempo económica, política y psicológico-cultural. ${ }^{9}$ Aquí nos limitaremos al aspecto económico. Acerca de los otros aspectos -que tratamos en otros textos- podemos decir en forma genérica que corresponden a la nueva asertividad de los asiáticos acerca de sus responsabilidades en el sistema internacional, una circunstancia relevante en este contexto en la medida que la diplomacia chilena la asimila gradualmente, contribuyendo a potenciar el interés en el Pacífico, el cual es, a su vez, reforzado a través de la participación de personeros de alto nivel en los foros regionales APEC, PECC y PBEC.

La transformación económica del Este de Asia ha dado origen a uno de los grandes debates en la literatura contemporánea sobre el desarrollo. El examen de este debate y la evaluación de los argumentos alternativos para explicar el enorme proceso de crecimiento dinámico de la región no es parte de nuestra tarea. ${ }^{10}$ Desde la perspectiva de nuestro análisis, la percepción -aún incompleta- que se tiene en Chile de la magnitud e importancia de este proceso ha estimulado el interés en el Este de Asia, incide en la priorización de ésta en la política exterior, y tiene además un carácter en cierto modo paradigmático dentro de las discusiones nacionales sobre las estrategias para que Chile pueda acceder a la condición de país desarrollado. Nos referimos, por supuesto, al debate sobre los posibles paralelos entre las experiencias de desarrollo de nuestro país y las de los tigres del Este de Asia.

\footnotetext{
${ }^{8}$ Ver la tesis de Juan Pablo Glasinovic "Análisis comparativo de la relación de Chile con Malasia e Indonesia, 1974-1994", escrita en el marco del proyecto FONDECYT 1950834, Santiago, Universidad Católica de Chile, Instituto de Ciencia Politica, 1995.

9 "The Revolution in East Asia", manuscrito inédito, 1994, citado con autorización del Dr. Sopiee.

${ }^{10}$ Banco Mundial, East Asian Miracle (hay sintesis en castellano: El Milagro de Asia Oriental, (Washington, D.C.: 1993).
} 
Siguiendo a Sopiee, podemos sintetizar los rasgos sobresalientes del cambio económico asiático en términos de tamaño, de dinamismo, de integración (regionalización), y de reestructuración hacia el predominio del mercado. ${ }^{11}$ Hacia 1950, el tamaño combinado de las economías del Este asiático era aproximadamente un sexto de la economía de los Estados Unidos y un tercio de la economía de Europa Occidentạl. En 1990 , las proporciones habían cambiado radicalmente: el producto total del Este de Asia equivalía a tres cuartas partes del producto de Europa occidental y a dos tercios del área NAFTA. Hacia el año 2010 (época en que las economías desarrolladas de APEC deberían haber liberalizado sustancialmente sus intercambios comerciales y flujos de inversión, de acuerdo al compromiso básico asumido en 1994 por los lideres en Bogor), se estima que el Este de Asia podría representar alrededor de un tercio del producto global, mientras Europa representaria aproximadamente la cuarta parte del mismo, y NAFTA una proporción similar. En otras palabras, si esta proyección se cumpliera, en el lapso de tan sólo seis décadas el Este de Asia habría pasado de una posición económica internacional marginal y subordinada a una posición de liderazgo, superando en tamaño a los tradicionales centros occidentales de la economía mundial. Ello habría ocurrido en circunstancias que en los primeros diez a quince años del período de postguerra, pocos observadores apostaban al éxito económico de esta región.

Este extraordinario cambio sólo ha sido posible en la medida que el Este de Asia ha crecido más dinámicamente que cualquier otra región del mundo en el periodo contemporáneo, tanto en términos de producto como -sobre todo- de comercio internacional. Desde mediados de la década de los 80 , más de la mitad del incremento del producto global se ha originado en el Este de Asia. Como ha destacado el conocido informe del Banco Mundial El Milagro de Asia Oriental, entre 1965 y 1990 el crecimiento de los países de Asia Oriental ( 23 economías en total) fue más rápido que el de todas las demás regiones, superando el nivel del $5 \%$ de crecimiento medio anual del PNB per capita.

Este crecimiento -que contrasta con tasas medias inferiores al $2 \%$ en América Latina y el Caribe, Oriente Medio y Mediterráneo, y Asia Meridional, y duplica con creces la tasa media de los paises OCDE- se explica fundamentalmente por el excepcional dinamismo (aparentemente milagroso, en términos del Banco Mundial) de ocho economías: Japón, los cuatro tigres (Hong Kong, Singapur, Taiwán y Corea del Sur)

${ }^{i 1}$ Sopice, op.cit. 
y los tres países de reciente industrialización del Sudeste asiático (Tailandia, Malasia e Indonesia). La tasa media de incremento anual del PNB per capita de estas economías en el cuarto de siglo comprendido entre 1965 y 1990 es del orden del 5,5\%. En cambio, si se omitiera estas economías del cálculo de la tasa regional, resultaría un crecimiento no superior al de los países OCDE. Por vía de comparación con uno de los miembros europeos más importantes de OCDE, se ha observado que, tan sólo en el período 1986-1991, el crecimiento económico en Japón fue equivalente a una economía del tamaño de Francia. Por supuesto, es necesario considerar, además de las economías asiáticas mencionadas, el caso de la República Popular China, que no se incluyó en el estudio comparativo del milagro, en atención a las profundas diferencias políticas y económicas entre China y su entorno regional. No cabe duda que uno de los principales desafíos del multilateralismo económico global y del Pacífico en las próximas décadas, será definir los términos de la participación de este futuro gigante económico. ${ }^{12}$

Como consecuencia de estos diferenciales en las tasas de crecimiento económico, la tendencia al cambio en el ranking de tamaño de los mercados nacionales $-\mathrm{y}$, por ende, a la traslación de los ejes de la actividad internacional- hacia el Este de Asia ha sido una señal de importancia para las nuevas orientaciones de la política exterior económica en los foros multilaterales del Pacífico. Este cambio tiene directa relación con el dinamismo del Sudeste asiático. En efecto, en 1992 eran dos las economías del Este asiático que se encontraban entre las diez mayores del mundo (en términos del PGB a paridad de poder adquisitivo, la llamada medida PPP): Japón (No) y China (No3). De acuerdo con proyecciones del Banco Mundial, hacia el año 2020 (cuando, de acuerdo a los compromisos de Bogor, APEC debería estar completando el proceso de liberalización por parte de todos sus miembros), seis de las diez mayores economias mundiales (en términos de PGB-PPP) podrían ser del Este de Asia: China (No1), Japón ( ${ }^{\circ} 3$ ), Indonesia $\left(\mathrm{N}^{\circ} 5\right)$, Corea del Sur $\left(\mathrm{N}^{\circ} 7\right)$, Tailandia $\left(\mathrm{N}^{\circ} 8\right)$ y Taiwán $\left(\mathrm{N}^{\circ} 10\right)$. Aunque es claro que proyecciones de este tipo siempre deben leerse con cautela, y el tamaño absoluto de las economías es sólo un aspecto de su inserción internacional, la irrupción del Sudeste asiático entre los principales actores económicos internacionales se insinúa como una

\footnotetext{
${ }^{12}$ Banco Mundial, op. cit. Ver Ross Garnaut, Asian Market Economies-Challenges of a Changing International Environment, (Singapur: ISEAS, 1994), p. 7. Este breve libro del economista australiano es una útil síntesis del tema del dinamismo del Asia Oriental.
} 
fuerte tendencia, que los demás actores de la Cuenca del Pacífico, entre ellos. Chile, solamente podrían ignorar a su propio costo. ${ }^{13}$

En cuanto al comercio internacional, la expansión del papel de la región ha sido muy rápida. Como señalan Drysdale y Garnaut, en 1980 el Este de Asia representaba un 13,7\% del comercio internacional (por debajo de Norteamérica, que tenía el 15,0\%). En 1990, la participación del Este de Asia había subido al 19,3\% del comercio global (superando ampliamente a Norteamërica, que tenía el 16,6\%). En el mismo período, la proporción del comercio internacional correspondiente a las economías que en 1989 formaron APEC subio de 30,1\% a 37,4\%. Según estos autores, hacia el 2000 el comercio APEC podria representar casi la mitad del comercio mundial $(48,7 \%)$, correspondiendo dos tercios de esta proporción a los miembros de APEC en el Este de Asja. ${ }^{14}$

Sin entrar - como ya se ha advertido- en la larga, aunque siempre fascinante, discusión acerca de los roles relativos de lo público y lo privado -el Estado y el mercado- en la gestación y la gestión de tan trascendentales transformaciones en cada una de las economías del Pacífico, 15 en ausencia de un acuerdo formal de comercio en APEC resulta incuestionable que los protagonistas del cambio en la región son fundamentalmente las empresas. Estos agentes económicos canalizan los crecientes flujos de comercio e inversion, actuando dentro de los marcos multilaterales y bilaterales de carácter politico-económico sustentados por los gobiernos y, al mismo tiempo, participan (y son convocados a participar) en la transformación liberalizadora de esos mismos marcos. Si bien son abundantes las barreras comerciales de toda índole que subsisten en la región, la orientación general de las politicas comerciales en el área ha sido liberalizadora. Así lo advierte Garnaut, cuyo juicio es confirmado por los estudios realizados por el Foro de Política Comercial de PECC a solicitud de APEC. Este marco favorable ha estimulado el comercio en el Pacífico, el que ha venido creciendo a una tasa que duplica la expansión del producto. La parte más significativa de este crecimiento

\footnotetext{
${ }^{13}$ Sobre el tema de las proyecciones, Sopiee, op. cit., y Malcolm Dowling, "Structural change and economic development in developing Asia in the 1990s", en: Seiji Naya y Akira Takayama (eds.), Economic Development in East and Southeast Asia-Essays in Honor of Professor Shinichi Ichimura, (Singapur y Honoluiu: ISEAS-East-West Center, 1990), p. 9 y ss.

${ }^{14}$ Ross Garnaut y Peter Drysdale, "The Pacific: An application of a general theory of economic integration", en: C. Fred Bergsten y Marcus Noland (eds.), Pacific Dynamism and the International Economic System, (Washington, D.C.: Institute of International Economics y Secretaría PAFTAD, 1993), pp. 183-184.

15 Ver la interesante discusion de la literatura por George Hicks, "Explaining the success of the four little Dragons: A survey", en: Naya y Takamaya (eds.), op. cit., pp. 20-37.
} 
ha tenido lugar al interior del Este de Asia, lo que potencia el papel de esta parte del Pacífico en el desarrollo general de la Cuenca.

En este sentido, el rol de la política multilateral chilena no podría apuntar a la fundación de un proceso que ya existía por iniciativa de otros actores, que ha tenido $\mathrm{y}$ sigue teniendo una dinámica que depende fundamentalmente de las interacciones del Este de Asia con el resto del Pacífico. Se trata más bien de integrar estrechamente a Chile a este proceso como un miembro activo en la macro-región del Pacifico, potenciando así los beneficios económicos y políticos de su recientemente adquirida condición de primer actor sudamericano en los asuntos de Asia-Pacífico. En este aspecto, vemos un contraste significativo entre el multilateralismo chileno en el Pacífico, que apunta a la incorporación chilena a un proceso dinámico, en el que cabría pensar en un papel de país-puente, y el regionalismo chileno en el contexto de la integración latinoamericana, que ha consistido en diversos intentos de fundación de áreas económicas, ninguna de las cuales ha alcanzado un dinamismo comparable al de Asia-Pacífico.

\section{El proceso de formación de la política.}

Bajo el gobierno militar, el naciente interés en el multilateralismo del Pacífico se basó, como se ha señalado, en una combinación de motivaciones geopolíticas, político-ideológicas, diplomáticas y económicas. Los actores que participaron en la primera fase de acercamiento a la Cuenca del Pacífico incluyeron diplomáticos de carrera, asesores políticos de orientación nacionalista como el abogado Mario Arnello, algunos empresarios y militares como el general Agustín Toro Dávila, designado embajador en Filipinas. En este período se atribuyó especial importancia al Pacífico insular, cuyos nacientes micro-Estados parecían abrir oportunidades políticas para Chile, en circunstancias que todavía no se diferenciaban claramente en la agenda los temas de intereses marítimos en la Cuenca, las estrategias bilaterales y multilaterales y la promoción de los intereses económicos.

En este último aspecto, como señala un estudio, se trataba de proyectar a Chile como un país económicamente estable y de gran

${ }^{16}$ Garnaut, Asian Market Economies, p. 21; Pacific Economic Cooperation Council, Survey of Impediments to Trade and Investment in the APEC Region, (Singapur: PECC, 1995); Pacific Economic Cooperation Council, Milestones in APEC Liberalisation: A Map of Market Opening Measures by APEC Economies, (Singapur: PECC, 1995); Pacific Economic Cooperation Council, Pacific Economic Outlook 1996-1997, (San Francisco: The Asia Foundation, 1996), p. 8. 
atractivo por la aplicación de un modelo económico de libre mercado. ${ }^{17}$ A nivel interno, esta política tenía la función política de demostrar que Chile no se encontraba aislado internacionalmente. Por esta misma consideración, el gobierno militar puso particular énfasis en la apertura de embajadas en Asia-Pacifico y en el establecimiento de relaciones concurrentes. Sin embargo, la abrupta cancelación de la visita oficial del general Pinochet a Filipinas, cuando ya se encontraba en viaje a ese país, significó un inesperado revés para la política, especialmente en la medida que precipitó la renuncia del Canciller Hernán Cubillos, quien había promovido el tema del Pacifico con un estilo pragmático y favorecía la priorización de la agenda económica en el área.

En este período, Chile inicia su participación en el Pacific Basin Economic Council (PBEC). En 1983 se realizó en Santiago la Asamblea Internacional Anual de este importante circuito empresarial del Pacifico, con la colaboración del Instituto de Estudios Internacionales de la Universidad de Chile. ${ }^{19}$ La presencia chilena en PBEC constituyó un avance significativo en el nivel no gubernamental. Sin embargo, la fuerte recesión económica del período y la crisis de endeudamiento externo de mediados de los años 80 limitaron el potencial de proyección en dirección al Asia-Pacífico.

En el período de transición democrática correspondiente a la presidencia de Patricio Aylwin, la política exterior se orientó a recuperar la presencia y participación de Chile en el sistema internacional, tanto en las relaciones bilaterales como en diversos foros multilaterales. Ello implicó destacar especialmente los temas políticos del retorno al régimen representativo de gobierno y al Estado de Derecho, particularmente en el ámbito del respeto y promoción de los derechos humanos, y otorgar prioridades muy altas a la normalización plena de las vinculaciones con Estados Unidos, los países de la Unión Europea y ciertos Estados de la región.

La composición del equipo conductor de la politica exterior correspondió en términos generales a estos criterios. El rol presidencial

\footnotetext{
${ }^{17}$ Luis F. Marco, "La Polttica Exterior de Chile y su Apertura al Asia-Pacifico", Universidad de Chile, Instituto de Estudios Internacionaies, tesis de Magister, 1995, p. 24.

${ }^{18}$ Sobre este tema, ver Maritza Arenas y Najel Klein, "Relaciones de Chile con Singapur, Tailardia y Fìlipinas", Universidad Católica de Chile, Instituto de Ciencia Política, tesis de Magister escrita en el marco del proyecto FONDECYT 1950834, 1996, p.78.

${ }^{19}$ Pilar Armanet, Pilar Alamos y Luz OShea, Las Relaciones de Chile con los Organismos Multilaterales de la Cuenca del Pacifico, (Santiago: Instituto de Estudios Internacionales de la Universidad de Chile y Fundación Chilena del Pacífico), 1996, p. 24.
} 
se puede describir fundamentalmente como un arbitraje y una participación selectiva en los temas, correspondiendo a la Secretaria General de la Presidencia, bajo Edgardo Boeninger, un papel central de contrel de la agenda y de coordinación interministerial. A nivel de la Cancillería, la visión internacional y el estilo diplomático del Ministro Enrique Silva Cimma y del Subsecretario Edmundo Vargas (ex Secretario Ejecutivo de la Comisión Interamericana de Derechos Humanos), se identificaban más con los temas políticos y jurídicos globales y latinoamericanos que con el multilateralismo económico en el Pacífico. El sucesor de Vargas en el último año del gobierno, anteriormente vicepresidente de la Comisión Chilena del Cobre, Rodrigo Díaz Albónico, aunque más interesado en los asuntos económicos, participaba del enfoque jurídico propio de la tradición diplomática ministerial. En este contexto, resultó fortalecida la participación en la diplomacia económica de los ministros de Hacienda, Alejandro Foxley, y de Economía, Carlos Ominami. El perfil de la política impulsada por estos actores se caracterizó por la profundización de la apertura externa chilena al comercio y la inversión extranjera, postura que se equilibró y complementó con la proyección internacional de los criterios de equidad a través de la iniciativa de realización de la Cumbre para el Desarrollo Social. Este tema tuvo fuerte respaldo presidencial y fue impulsado en Naciones Unidas por el_embajador Juan Somavía. Aunque en principio desligado del multilateralismo del Pacifico, el tema de la equidad internacional proveyó una base de diálogo con actores asiáticos como Malasia, aliado clave en la campaña de ingreso a APEC.

En las direcciones ministeriales, funcionarios claves como Carlos Portales, Director General de Política Exterior; Augusto Aninat, Director General de Relaciones Económicas Internacionales; y José Miguel Insulza, Director de Asuntos Económicos Multilaterales, contribuyeron a la formulación y puesta en marcha de la política exterior económica dentro de los lineamientos descritos, lo que permitió retomar, desde fines del primer año del gobierno, el impulso de la politica de incorporación a los foros del Pacífico. Portales apoyó decididamente esta política en todas sus fases, mientras Aninat estuvo por subir el perfil de las relaciones con los países del Sudeste asiático, especialmente Malasia, para promover los intereses económicos chilenos en la subregión y en el plano multilateral. La coordinación de esta política recayó en el diplomático de carrera Octavio Errázuriz, quien tuvo a su cargo los temas PECC y APEC, bajo dependencia directa de Portales. Desde el 
Ministerio de Hacienda, el asesor intemacional del Ministro Foxley, Juan Salazar, embajador en Australia en el período fundacional de APEC, participó activamente en estos temas. En Economía, el interés en el Pacífico se concentró especialmente en el Comité de Inversiones Extranjeras, dirigido entonces por su vicepresidente, Roberto Mayorga.

Tal vez la característica más importante del proceso de gestación y desarrollo de la política del Pacífico en el período 1990-1994 fue la conformación dé una coalición informal, no partidista, entre actores públicos, privados: $y$ académicos, especialmente en torno a la participación en PECC a través del Comité Chileno de Cooperación en el Pacífico (CHILPEC). 'A pesar que la convocatoria de CHILPEC estuvo condicionada por el origen ministerialsde la entidad, bajo la coordinación de Errázuriz, se sumarón`al esfuèrzo 'gubetnamental representantes de entidades importantes del sector empresarial,; como la Cámara Nacional de Comercio, la: Sociedad de Fomento Fabril y la Asociación de Exportadores. Asimismo, se amplió lä participación del sector público a instituciones como el Banco Central y la Comisión Chilena del Cobre; y se incorporaron académicos y especialistas de centros de larga trayectoria, como el Instituto de Estudios Internacionales de la Universidad de Chile, así como de universidades privadas y de otros centros de estudio, algunos de los cuales sirvieron de puente entre el mundo académico y el sector político, que recién comenzaba a enfrentar el tema del Pacifico. 20

Durante la gestión del primer Canciller del gobierno del Presidente Frei, Carios Figueroa, la política del Pacífico cobró un nuevo impulso en el marco de la incorporación chilena a APEC, acordada a fines de 1993 (formalizada en la reunión ministerial de Bogor; en el intertanto, Chile participó en los grupos de trabajo). La gestión de los asuntos de APEC y PECC se radicó en la Dirección General de Relaciones Económicas Internacionales.(DIRECON), encabezada por Juan Salazar, mientras Octavio Errázuriz era designado embajador en Malasia.

\footnotetext{
${ }^{20}$ Entre estos centros cabe destacar el Centro Latinoamericano de Economía y Política Internacional (CLEPI), entidad integrada por un grupo de economistas; entre ellos Patricio Leiva, Sergio Bitar y Carlos Ominarni. Roberto Madrid, investigador de CLEPI, colaboró en la secretaría técnica de CHILPEC. Durante la campaña presidencial de 1993, la preparación de la propuesta programática sobre el Pacífico de la candidatura de Eduardo Frei estuvo a cargo de un subcomité coordinado por Juan Salazar y el autor de este artículo. El informe fue aprobado sin observaciones por la comisión prográmática de relaciones internacionales, coordinada por Pilar Armanet, Eduardo Aninat y José Miguel Insulza. Una sintesis de dicha propuesta se incorporó al documento programático central. Este ejercicio demostro que a nivel partidista había apoyo para avanzar en los temas del Pacífico, pero sin que estos se consideraran prioritarios por los diversos sectores politicos participantes en la Concertación.
} 
Con el fin de fortalecer la participación tripartita en CHILPEC, PECC y de implementar otras iniciativas como el Centro de Estudios APEC de Chile, el Ministro Figueroa propuso al ex-Ministro:Edgardo Boeninger encabezar una nueva entidad autónoma, que sería la Fundación Chilena del Pacífico, la que asumiría la gestión de CHILPEC. La fórmula fue ratificada por el sucesor del Ministro Figueroa, el Subsecretario José Miguel Insulza, y encontró amplio respaldo en los sectores empresariales $\mathrm{y}$ académicos ya integrados a CHILPEC, además de nuevos participantes convocados por Boeninger y Salazar. Junto con permitir a DIRECON concentrarse en la vasta y exigente agenda de APEC, la nueva entidad permitiría subir el perfil de la participación nacional en diversos foros multilaterales del Pacífico, asumiendo, entre otras responsabilidades, la organización de la XII Reunión General de PECC (PECC XII), convocada para fines de septiembre de 1997. La decisión del Comité Permanente PECC de aceptar la solicitud chilena de celebrar PECC XII en Santiago fue la culminación de un paciente trabajo de lobbying entre los miembros del Comité, especialmente por parte de Juan Salazar y la encargada de PECC-APEC, Cristina Bitar.

En 1995, a raíz de diferencias interministeriales sobre la gestión de los asuntos de NAFTA, Salazar, quien había tenido un papel protagónico en la política multilateral del Pacífico y en el establecimiento de la Fundación, renunció a su cargo, si bien-estando ya en el sector privadoaceptó integrar el grupo asesor de APEC denominado Eminent Persons Group, que funcionó hasta fines de ese año. Su sucesor, el ex Subsecretario de Economía, Carlos Mladinic, aunque sin participación previa directa en los asuntos del Pacífico, continuó la política del equipo anterior. En septiembre de 1996, Mladinic fue designado Ministro de Agricultura, y posteriormente Juan Gabriel Valdés asumió la jefatura de DIRECON. Valdés, desde el Ministerio de Hacienda, había estado a cargo de NAFTA y de la negociación comercial con Canadá. A pesar de la considerable rotativa directiva en DIRECON, el compromiso efectivo con las políticas multilaterales del Pacífico se ha mantenido.

De esta manera, se han establecido las bases para una gestión estable de la creciente agenda multilateral del Pacífico, la que paulatinamente se fortalece a través de la coordinación con el sector privado, y recurre a los aportes del incipiente conocimiento académico sobre el área. Ens este contexto, que evaluamos como positivo pero mejorable, la principal dificultad que se encuentra en el camino de la estrategia chilena no es de naturaleza política, sino organizativa. Frente a la multiplicación de foros 
del Pacífico, con sus respectivas instancias de trabajo, un país pequeño como Chile-empeñado, además, en una estrategia, de inserción regional múltiple-tiene grandes problemas para desplegar contingentes funcionarios, empresariales y académicos suficientes en cantidad y calidad para responder eficientemente ante las grandes demandas que impone la participación en los asuntos multilaterales del Pacífico. Esta realidad impondría la necesidad de algún tipo de estrategia de participación selectiva, para lo cual no se cuenta hasta ahora con criterios de decisión.

Chile y los tres foros del Pacífico.

Trataremos sucesivamente la participación chilena en los tres principales foros multilaterales del Pacífico-PBEC, PECC y APEC-sin detenernos en la historia de algunos esquemas multilaterales que no han tenido mayor impacto en la cooperación internacional en el área. En términos generales, la participación chilena muestra una clara curva ascendente a través del tiempo, proyectändose entre los años 80 y 90 hacia foros de creciente tamaño, complejidad e importancia. Se inicia esta participación multilateral en PBEC, continúa en PECC y culmina en APEC. De los tres foros, indudablemente APEC ha emergido como el de mayor importancia, en la medida que constituye la red de los gobiernos para elaborar consensos progresivos acerca de la liberalización de los intercambios en el Pacífico. Aunque, como se ha advertido, las relaciones de comercio, financiamiento e inversión son predominantemente privadas, los gobiernos son actores centrales en lo concerniente a las estructuras y marcos bajo las cuales operan los agentes privados. Al mismo tiempo, su diálogo acerca de la liberalización de estos aspectos se encuentra expuesta a las demandas y propuestas que emergen desde lo que podríamos llamar una emergente sociedad civil del Pacífico, la que se articula tanto a través de los foros anteriores a APEC y en torno a esta entidad, configurando redes de relaciones cada vez más complejas y entrelazadas. El desafio de una participación efectiva chilena pasa por el conocimiento, utilización e inserción eficaz en estas redes. 


\section{PBEC: el circuito empresarial.}

Durante sus tres décadas de funcionamiento, el Pacific Basin Economic Council, fundado en 1967 , se ha perfilado como el principal circuito empresarial transnacional del Páfífico. 21

A nivel interno, funciona un Comité Nacional del PBEC, el que desde 1994 tiene el apoyo administrativo de la Sociedad de Fomento Fabril. Los miembros del Comité Nacional son personeros asociados a diversas empresas chilenas y algunas extranjeras (como Mitsubishi, Carter Holt Harvey y Minera Escondida). Se trata principalmente de grandes empresas, sin perjuicio de algunas medianas; participan además algunas instituciones de educación superior, como la Universidad Gabriela Mistral, aunque no se reconoce en PBEC una orientación a la actividad académica en torno a los asuntos del Pacífico. Por último, aunque la regla general es que los integrantes son entidades privadas, participa en PBEC-Chile al menos una empresa estatal (Sipetrol, filial de la Empresa Nacional del Petróleo, ENAP) y una universidad estatal (la Universidad de Santiago de Chile, USACh).

Dentro de lo que Pilar Armanet et al. llaman el estilo suelto y flexible de PBEC $^{22}$ no tiene cabida en este foro multilateral el desarrollo de una capacidad de generación de propuestas de políticas públicas para la liberalización de las relaciones económicas en la Cuenca del Pacífico. De hecho, con la excepción de las citas periódicas del Comité Directivo, que por su propia indole son de bajo perfil, PBEC es un circuito que se activa en alto grado solamente con motivo de sus asambleas anuales. Estas reuniones -que gradualmente van asumiendo el carácter de megaeventos del Pacífico- son ocasiones propicias para la discusión de una filosofía de libre empresa y libre comercio en la región, así como para un limitada comunicación entre empresarios y personeros públicos y académicos invitados como expositores. Pero, en la práctica, la función de comunicación informal (el llamado networking de pasillo ơ en la cancha de golf) entre los hombres de negocios y demás participantes en las reuniones generales parece tener tanta importancia como la propia asamblea.

\footnotetext{
2! Los Comités Nacionales del PBEC son Australia, Canadá, Chile, Colombia, Corca, Estados Unidos, Filipinas, Fiji, Hong Kong, Indonesia, Japón, Malasia, México, Nueva Zciandia, Perú, República Popular China, Tailandia y Taiwán. Pilar Armanet et. al., p. 24, no incluyen a China, Indonesia y Tailandia, paises que registran delegados de Comités Nacionales en la 29a Reunión General Intemacional (Washington, D.C., mayo 1996).

22 Op. cit., p. 24.
} 
En estas circunstancias, desde el punto de vista del gobierno no es necesaria ni pertinente la formulación y puesta en práctica de una política hacia este foro, más allá del esfuerzo, coordinado con los empresarios del Comité Nacional; en el sentido de proyectar la mayor y mejor imagen posible de Chile como una economía crecientemente abierta, competitiva e integrada a la Cuenca del Pacífico. Así lo han entendido sucesivos gobiernos, especialmente el actual, que se ha hecho presente en las asambieas generales de PBEC a través de un mensaje presidencial en video, ${ }^{23}$ de oradores a nivel ministerial, ${ }^{24}$ y que ha apoyado la realización de la cita anual de PBEC en Chile para 1998 . $^{25}$

Las diferencias que suelen plantearse entre gobierno y empresarios en temas de política económica interna carecen de relevancia en el contexto que se ha descrito, lo que ha contribuido a mantener despolitizada la participación chilena en PBEC.

\section{PECC: el foro tripartito.}

El Consejo de Cooperación Económica del Pacífico (PECC) se constituyó en 1980, a partir de conversaciones entre los'gobiernos de Japón y Australia sobre el tema del futuro de la cooperación en el Pacífico. Los actores centrales fueron el Primer Ohira y el Canciller Saburo Okita y el Primer Ministro Malcolm Fraser, Sin duda, esta iniciativa tuvo mucho que ver con la búsqueda japonesa de un rol constructivo en el área, que ayudara a Tokio a superar percepciones negativas en Asia-Pacífico, y con la búsqueda australiana de vías apropiadas para acercarse al Asia, en el contexto del alejamiento progresivo de la diplomacia de Canberra de su tradicional orientación anglosajona. Pero en la perspectiva más amplia del Pacífico, está claro -en visión retrospectiva- que la coincidencia de criterios entre los fundadores permitió lanzar una idea de grandes proyecciones en el momento adecuado, esto es, en la década en que AsiaPacifico se perfiló como una región gravitante en la escena económica global.

Desde un comienzo, se entendió que PECC debía promover la cooperación económica en el Pacifico combinando los enfoques y la

\footnotetext{
${ }^{23}$ Mensaje del Presidente de la República a la $28^{\text {n }}$ Reunión General Anual, Auckjand, Nueva Zelandia, mayo 1995.

${ }^{24}$ Participación del Ministro Presidente de la Comisión Nacional de Energía, Alejandro Jadresic, en la $28^{*}$ Reunión Genetal Internacional en Auckland, Nueva Zelandia, 1995, y del Ministro de Economia, Alvaro García, en la $29^{*}$ Reunión en Washington D.C., mayo 1996.

${ }^{25}$ Resolución adoptuda en la $29^{4}$ Reunión a propuesta del Conité Directivo, respondiendo a una petición del Comité Chileno, la que obtuvo el respaldo del Gobierno.
} 
participación del sector público, del mundo empresarial y de los sectores académicos de los países participantes. Este esquema ha servido el doble propósito de aprovechar los aportes intelectuales y privados para ampliar la base de sustentación de la cooperación, manteniendo al mismo tiempo un perfil gubemamental bajo en materias que suelen ser políticamente sensibles.

Asimismo, a través de la organización de diferentes grupos de trabajo y foros sectoriales al interior de PECC, se manifestó la voluntad de generar propuestas de políticas de cooperación susceptibles de convertirse en opciones a disposición de los gobiernos interesados. Este carácter tripartito y orientado a las políticas multilaterales ha diferenciado nítidamente a $\mathrm{PECC}$ de las entidades regionales puramente empresariales, académicas o intergubernamentales, $y$ ha sido una clave de la adaptabilidad, flexibilidad, persistencia e influencia de este foro del Pacifico.

Otra característica relevante ha sido la descentralización: la instancia decisoria en PECC es el Comité Permanente (Standing Committee), integrado por los presidentes de los Comités Nacionales, encabezado por el presidente del país (economía) organizador de la próxima Reunión General. La secretaría, a cargo de un Director General, es de tamaño reducido y se limita cumplir funciones de coordinación y apoyo. Esta circunstancia ha ayudado a mantener desburocratizado el funcionamiento del PECC. ${ }^{26}$

\footnotetext{
${ }^{26}$ Pilar Armanet et al., op. cit., pp. 31-47, sintetizan los antecedentes relevantes de la trayectoria y características del PECC. En 1996, integran el PECC los Comités Nacionales de Australia, Brunei, Chile, China, Colornbia, Corea, Estados Unidos, Filipinas, Hong Kong, Indonesia, Japón, Malasia, México, Nueva Zelandia, Perni, Rusias, Singapur, Taipei Chino (Taiwán), Tailandia y Vietnam. También tiene calidad de miembro el South Pacific Forum, que agrupa diversos Estados insulares đel Pacifico. Además, forma parte del Conité Permanente el Presidente Internacional del PBEC, pero en la práctica PBEC no se ha hecho presente en las reuniones del Comité por varios afios. Es interesante, por otra parte, observar las pequeñas pero significativas diferencias entre la composición de PECC y la de APEC. Primero, PECC tiene un componente latinoamericano mucho más importante (Peru y Colombia se agregan a Chile y México). Segundo, Rusia, ausente de APEC, está en la entidad, aunque la participación rusa ha sido bastante débil. En septiembre de 1996, el Comité Permanente acogió la postulación de Vietnam. Papúa Nucva Guinea es el único país miembro de APEC que no forma parte de PECC. Con esta única excepción es posible, por lo tanto, afirmar que los asuntos de APEC tienen interlocutores privados y académicos organizados en Comités Nacionajes PECC en todas las economias participantes, mientras que PECC tiene mayor cobertura geográfica. Obviamente, en algunos miembros de PECC los agentes privados:y académicos carceen de autonomia, situación que escapa a nuestro objeto de análisis. En cuanto a la Secretaria, cabria reconocerle cierto margen de intluencia en la medida que la presidencia del Comité Permanente no sea particularmente activa, lo que no parece ser la regla general. En el caso de Chile, la comunicación con PECC ba sido facilitada por la comisión de servicio de un funcionario de la Cancillería, Enrique Subercaseaux, en dicha Secretaria. Subercaseaux es el mejor conocedor del medio asiático entre los funcionarios a nivel de Primer Secretario.
} 
Durante el gobierno militar, la constitución de un Comité de Cooperación en el Pacífico fue un elemento de la estrategia de acercamiento al área y específicamente al PECC. Sin embargo, a pesar que se comenzó a constituir grupos de trabajo en torno a los temas de este foro y se manifestó la aspiración chilena de ingreso al mismo, la política del Pacífico aún era vacilante y hasta cierto punto secundaria dentro de la diplomacia militar (sobre todo después del incidente filipino de 1980), y la hipótesis que a través de ella se podria haber pasado por alto las falencias políticas de la política exterior del período no pasaba de ser una especulación sin fundamento claro.

En cambio, la reinserción internacional de Chile a partir de 1990 , unida a la creciente percepción de Chile como un caso excepcional de progreso económico en una América Latina sumida en el estancamiento, favoreció el ingreso al PECC. Este se concretó en la VIII Reunión General (Singapur, 1991). A nivel interno, se realizó en este período un importante esfuerzo de ampliación del Comité Chileno de Cooperación en el Pacífico, que en la terminología de PECC se conocería como CHILPEC (Chilean Committee on Pacific Economic Cooperation).

A nivel de la región, el esfuerzo político de la entidad tripartita por influir en el curso de la liberalización económica tiene lugar esencialmente a través de una serie de grupos de trabajo, programas y foros especializados, los que sustentan técnicamente las deliberaciones del Comité Permanente. Como se verá a continuación, en los primeros cinco años de participación chilena en PECC, la característica más importante del rol chileno ha sido la creciente actividad en las instancias de discusión. Esta tendencia ha cambiado progresivamente el estilo de participación de la retórica general a la discusión de propuestas de política.

\section{Foro de Política Comercial (Trade Policy Forum, TPF).}

Este foro es probablemente el más importante de los grupos PECC. Coordinado por el Comité de Indonesia, en estrecha colaboración especialmente con los Comités de Australia y Taiwán, esta instanciia reúne, bajo el esquema tripartito, a un influyente conjunto de especialistas en relaciones económicas internacionales de prácticamente todas las economias PECC. Las reuniones periódicas del TPF, que han asumido un carácter crecientemente técnico, dan origen a propuestas que son refrendadas por el Comité Permanente y comunicadas de manera principal, pero no exclusiva, a las instancias pertinentes de APEC, como el 
Comité de Comercio e Inversión (CTI) y la reunión de los altos funcionarios nacionales (SOM), con el propósito de impulsar la liberalización económica en el Pacífico.

Por su parte, el Comité Permanente considera eśpecialmente los aportes del TPF para la elaboración de documentos y declaraciones dirigidas a las reuniones APEC a nivel ministerial, en las que PECC actúa como observador oficial. Asimismo, ha ido ganando terreno la práctica de rodear las principales reuniones de APEC de grandes encuentrós ampliados organizados por PECC, lo que contribuye a intensificar el diálogo de los gobiernos con el establishment del Pacífico agrupado en PECC (PBEC suele asociarse a este tipo de iniciativas, como ocurrió en 1994 y 1995 con motivo de las reuniones ministeriales de Bogor y Osaka, respectivamente).

Ultimamente se ha considerado que la Organización Mundial de Comercio debe ser también un destinatario de las propuestas del TPF, lo que es consistente con la abogacía de una política de regionalismo abierto en la que el Pacífico podría ser el impulsor de una futura profundización de los logros de la Ronda Uruguay.

Algunos de los temas principales del TPF en los últimos años son las barreras arancelarias y no arancelarias, el comercio de servicios, el impacto comercial de las reglas de origen, comercio y medio ambiente, y las políticas de competencia. La participación chilena en la discusión de esta agenda ha sido creciente, especialmente a partir de la reunión TPF 8 (Taipei, abril 1995), pero se ha circunscrito básicamente a los sectores público y académico, evidenciándose un déficit de participación empresarial.

En 1996, el esfuerzo chileno en el ámbito del TPF se concentró en propiciar el ingreso del sector privado a la discusión de la agenda, especialmente con motivo de la reunión TPF 9 (Seúl, septiembre 1996), y a programar un importante examen de la misma, en una perspectiva trans-Pacífico, en una sesión concurrente de la XII Reunión General PECC(Santiago, 1 de octubre 1997). El principal instrumento para lograr estos objetivos en Chile es el Subcomité de Política Comercial constituido en el seno de CHILPEC por la Fundación Chilena del Pacífico, grupo que cuenta con cerca de 50 miembros.

\section{Pacific Economic Outlook.}

Este programa PECC tiene por objeto la investigación y difusión de tendencias económicas en el Pacífico. La coordinación, a cargo de los 
Comités de Estados Unidos y Japón, ha logrado convocar a importantes economistas de toda el área PECC para la elaboración de informes anuales de coyuntura que se publican y difunden ampliamente, con apoyo de auspiciadores privados.

La participación chilena en este programa -que cuenta con el concurso del Banco Central--es importante en dos sentidos: ha permitido a CHILPEC dar a conocer las perspectivas y logros macroeconómicos del país, y ha mejorado la comunicación entre economistas chilenos y sus colegas de las economías PECC. De este modo se incrementa el nivel del conocimiento disponible en Chile sobre las economías de Asia-Pacífico. ${ }^{27}$

\section{Finanzas y Mercados de Capitales.}

El programa denominado Financial Markets Development (FMD) se inició a partir de la constatación de la importancia fundamental del desarrollo de los mercados de capitales, de los servicios financieros y de los regímenes de inversión extranjera en la dinámica económica de la Cuenca del Pacífico. Bajo coordinación de los Comités de Estados Unidos y Japón, a través de entidades privadas, el programa FMD ha tenido un fuerte crecimiento y se ha propuesto como meta estratégica impulsar la liberalización financiera en APEC, tema de los Ministros de Finanzas que incide tanto en las políticas internas de los paises como en los flujos financieros internacionales de la región.

La participación chilena en este programa se incrementa a partir de 1995, cuando CHILPEC organiza un Subcomité de Finanzas y Mercado de Capitales de CHILPEC, grupo de composición tripartita que orienta la presencia chilena en FMD a enfatizar la progresiva desregulación, liberalización e internacionalización del sector financiero en Chilé, así como la relevancia de las experiencias del país en materia de inversión institucional para la canalización del ahorro hacia la inversión. Hacia fines de 1996, FMD había avanzado en la elaboración de un primer informe a los Ministros de Finanzas de APEC, con importante participación chilena, especialmente en lo referente al papel de los fondos de pensiones en el desarrollo de los mercados de capitales en la región.

\footnotetext{
${ }^{27}$ Además de los informes de coyuntura, este programa ha abordado temas estructurales, los que no han tenido impacto público.
} 


\section{Alimentación y Agricultura.}

El Foro de Alimentación y Agricultura (Food and Agriculture Forum, FAF), coordinado por el Comité de Estados Unidos, ha abordado el tema, particularmente sensible en las relaciones económicas trans-Pacífico, del comercio internacional de productos agrícolas.

El creciente interés entre los miembros de PECC en las actividades del FAF se debe a varios factores. El primero es, sin duda, la percepción de grandes oportunidades económicas, en la medida que se abre el enorme potencial de los mercados asiáticos de alimentos y productos agrícolas, respondiendo a cambios como los aumentos en los niveles de bienestar en las economías emergentes de la región. El segundo factor es la fuerte incidencia de los productos agrícolas en las exportaciones de economías PECC tan diversas como, por ejemplo, Estados Unidós, Australia, Tailandia y Chile. En tercer lugar, es importante la persistencia de numerosos elementos de proteccionismo en las políticas nacionales, lo que justifica su identificación, estudio y discusión orientada a su reducción y eventual remoción. Este último aspecto cobra vigencia en el contexto de la adopción del criterio de liberalización comprensiva (esto es, de liberalización que no excluya los sectores agrícolas de las economías participantes) en la reunión ministerial de APEC de Osaka en 1995.

La participación chilena en FAF cobra impulso a partir de 1995, con motivo de la reunión concurrente agrícola en PECC XI, celebrada en Beijing. Para fortalecer la presencia chilena, CHLPEC ha organizado un Subcomité que es contraparte del FAF, y que procura priorizar en éste los temas de mayor interés nacional, como el comercio hortofruticola y de productos agroindustriales.

\section{Foro de Minerales y Energía.}

El Foro de Minerales y Energía (Minerals and Energy Forum, MEF) es coordinado por el Comité australiano, $y$ ha enfocado su trabajo al estudio del comercio de productos mineros en el Pacífico y las politicas de exploración y explotación en las economias PECC, con énfasis en las condiciones de la inversión extranjera en minería e hidrocarburos. En la práctica, la coexistencia de los sectores de mineria y energía en un solo foro ha frenado el desarrollo de los temas energéticos, puesto que estos se han abordado como una segunda prioridad, centrada en los aspectos de privatización y marco regulatorio. Ello ha motivado una reciente 
decisión del Comité Permanente de establecer un grupo energético separado del actual MEF, el que continuará a cargo del área de minerales.

Chile, como economía exportadora minera fuertemente vinculada a los mercados consumidores del Pacífico, así como a la tecnología y la inversión en el área, es un participante llamado a jugar un papel de importancia en el MEF. La vinculación de CHILPEC con este foro partió a través de la Comisión Chílena del Cobre, y desde la reunión MEF 7 (Manzanillo, México, abril 1996) se ha incrementado significativamente. $^{28}$

Existen otros foros e instancias PECC en temas tan variados como transportes, telecomunicaciones, turijsmo, pesquerías y recursos humanos. Por lo general, estos grupos tienden a acercarse crecientemente a sus contrapartes o instancias equivalentes de APEC. En la mayoría de ellos, Chile se ha hecho presente en los últimos años, aunque es necesario precisar que ninguno de estos grupos ha alcanzado niveles de influencia en la agenda de cooperación comparabies a los foros y grupos anteriormente reseñados.

La conclusión general del análisis precedente es que la presencia chilena en PECC, aủn bajo las nuevaş circunstancias de participación en APEC, es un elemento central del multilateralismo chileno en el Pacífico. Aunque PECC no negocia acuerdos ni compromete política $O$ económicamente a los gobiernos, es un foro clave para la socialización y reclutamiento de los actores nacionales en los temas de Asia-Pacífico, así como para la articulación de las políticas oficiales en APEC.

\section{APEC: El foro intergubernamental.}

Drysdale y Elek, siguiendo a Ippei Yamazawa, caracterizan a APEC como una asociación económica abierta. La apertura de APEC está dada por el carácter no discriminatorio del proceso de cooperación, y -en principio- por carecer de una estructura cerrada de participación (en la práctica esto es unitanto diferente, ya que los miembros más influyentes de APEC desean mantener limitada la participación mientras se define e implementa la carta de navegación de la entidad, lo que se refleja en la moratoria de nuevas admisiones acordada con motivo del ingreso de México, Chile y Papúa Nueva Guinea).

\footnotetext{
${ }^{28}$ El Ministro de Minería encabezó la representación chilena, que incluyó por primera vez a un especialista del sector privado. Con motivo de la XII Reunión General del PECC, se celebratá en Santiago el $8^{\circ}$ Foro de Minerales PECC.
} 
APEC es una entidad económica en cuanto procura promover la cooperación e integración de sus miembros en torno al comercio, la inversión y la cooperación para el desarrollo, de manera de difundir entre sus miembros los beneficios del crecimiento de la producción y el intercambio. Ello excluye, en principio, la agenda política, aunque, como es obvio, la cooperación económica es un tema inseparable de la política exterior de los miembros. Aunque en la jerga de APEC se identifica a estos como economías, no es un misterio que este término es solamente un eufemismo para referirse a países representados por gobiernos. Aparte del deseo de subrayar el carácter económico del foro, el uso adoptado tiene por objetivo posibilitar la participación de Taiwán (para estos efectos, Taipei Chino) y Hong Kong junto a la República Popular China, evitando los conflictivos temas de reconocimiento de Taiwán y-desde mediados de 1997- permitiendo la permanencia de Hong Kong en APEC.

En tercer lugar, APEC es una asociación que opera sobre la base del principio de coordinación de politicas por consenso de sus miembros. Este rasgo, tal vez el más original e importante de los mencionados, a la vez que el más asiático, diferencia a APEC de las entidades de integración convencionales, que se constituyen como organizaciones internacionales dotadas de estructuras formales, sistemas de votación para la adopción de resoluciones y acuerdos jurídicamente vinculantes y - como en el caso europeo-poderes centrales. ${ }^{29}$

Las características reseñadas no se perfilaban claramente cuando el gobierno chileno emprendió su campaña diplomática de ingreso a APEC. La entidad podía evolucionar hacia una zona de libre comercic del Pacífico, un foro de diálogo sobre el desarrollo o una instancia mixta de cooperación y negociaciones económicas. Lo que sí se vislumbraba con certeza era que el foro tenía una gran importancia potencial, y que para una economía cada vez más vinculada a la Cuenca del Pacífico, como Chile, quedar fuera de APEC podía significar la pérdida de una oportunidad histórica de participar en la mayor transformación económica de fines de siglo.

En 1991, el gobierno envió la primera nota solicitando ingresar como observador en la III Reunión Ministerial de APEC (Seúl). ${ }^{30}$ En ese

\footnotetext{
${ }^{29}$ Peter Drysdale y Andrew Elek, "Towards APECs Liberalization Goals of 2010 and 2020", en: Ippei Yamazawa y Akira Hirata (eds.), APEC: Cooperation from Diversity, (Tokio: Institute of Developing Economies, 1996), pp. 121-122.

${ }^{30}$ Ch. Signorio, op. cit., Capitulo 5.
} 
instante aún no se configuraba la polítiça de inserción regional múltiple de la economía chilena. Si bien Estados Unidos ya había anunciado la Iniciativa para las Américas, y el gobierno había respondido que Chile estaba listo para negociar un acuerdo de libre comercio regional, aún no existía NAFTA. La vinculación con Europa era un proyecto político que debía traducirse en un acuerdo de cooperación sin mayores facilidades en materia comercial, y el MERCOSUR recién se había firmado, sin que se perfilara una eventual participación chilena en el nuevo bloque subregional.

A partir de 1992, la campaña chilena cobró impulso con ocasión de la gira presidencial a Malasia, La República Popular China y Japón. Entre estos países -y entre todos los miembros de APEC- Malasia surgiría como el principal apoyo político de la iniciativa chilena. Malasia tenía la gran ventaja de pertenecer al bloque subregional ASEAN, agrupación que por sí sola representabä un grupo de gran peso en APEC (con seis de los entonces quince miembros), y que tenía interés en mantener las puertas de la entidad abiertas a nuevos miembros, como Papúa Nueva Guinea (observador en ASEAN, propuesto por Indonesia), y eventuales nuevos integrantes de ASEAN (consideración importante en el contexto de la pacificación de Indochina). Por medio de esta estrategia se trataba tanto de incrementar la influencia del Sudeste asiático como de prevenir el riesgo de una dilución de ASEAN en el contexto mayor de APEC. En Malasia, la causa del ingreso chileno llegó rápidamente a tener el apoyo personal del Primer Ministro Mahathir, lo que se debió, entre otros factores, a la excelente relación personal establecida desde 1991 con el Presidente Patricio Aylwin, quien retribuyó en noviembre de 1992 la visita que hiciera a Chile el gobernante asiático el año anterior. ${ }^{31}$

En Tokio no se logró un respaldo claro al interés chileno, ya que la propuesta era muy nueva para Japón y la preeminencia de los temas bilaterales en la agenda era muy considerable. Mientras tanto, en Australia y Estados Unidos se perfilaban posturas opositoras al ingreso de Chile. En Canberra, la oposición se debía a la ausencia de una prioridad latinoamericana en la diplomacia australiana, y al temor de una ampliación prematura de una entidad multilateral que no estaba consolidada y que comprometía el prestigio australiano.

En Washington, los policy makers de la política asiática en el Departamento de Estado consideraban que Chile estaba fuera del esquema regional de actores que debia ayudar a Estados Unidos a ${ }^{31}$ Juan Pablo Giasinovic, op. cit., p. 77. 
equilibrar fuerzas frente a las tendencias exclusionistas de la Unión Europea y las pretensiones regionalistas del tipo East Asia Regional Grouping (redenominado East Asian Regional Caucus ante las primeras señales de fuerte oposición estadounidenese). La idea de un EAEC era propiciada por el Dr. Mahathir como subgrupo dentro de APEC, o aún como alternativa a APEC en la medida que-según la perspectiva asiática de Kuala Lumpur- APEC podría convertirse en un instrumerito de los intereses politicos occidentales. En este contexto de debate, el eventual ingreso de Chile era, a los ojos de los funcionarios a cargo del Este de Asia, más bien un factor de distracción en las politicas de Washington. No ocurría to mismo en el caso mexicano, que agregaba peso a la participación estadounidense en la medida que se constituía un bloque NAFTA dentro de APEC. Mientras Chile argumentaba que las razones en favor de México no eran más antiguas o válidas que las chilenas, de hecho la solicitud chilena no hacía más que estorbar a los Estados Unidos. El rechazo de Washington, si bien menos evidente que el de Australia, se presentó como una posición neutral y de eventual disposición a acatar el consenso, ${ }^{32}$ política que obviamente esquivaba el problema de fondo: no surgiria el consenso si Washington no tenía interés en el ingreso de Chile. Si bien Estados Unidos, como Chair de APEC en 1993, debía registrar los consensos $\mathrm{y}$, por tanto, mantener un equilibrio, el liderazgo en APEC depende decisivamente de la economía organizadora de la Reunión Ministerial y que ejerce la presidencia.

En el primer semestre de 1993 se fueron perfilando los alineamientos de los miembros de APEC en torno al ingreso de Chile. El núcleo favorable a Chile era ASEAN, agregándose a este apoyo China y Nueva Zelandia. No se contaba con apoyo de Japón, Hong Kong y Canadá, mientras en Australia aparecía una disparidad de criterios entre el Primer Ministro Keating (opuesto al ingreso de Chile) y el Canciller Gareth Evans (a favor). México mantenía una retórica de apoyo, pero al parecer el gobierno mexicano temia que la fórmula del ingreso conjunto de México, Papúa Nueva Guinea y Chile pudiera perjudicar sus perspectivas.

Las solicitudes de ingreso de las tres economías se presentaron a la reunión de altos funcionarios (SOM) de Seattle en julio de 1993, sin que en esa reunión ni en la conferencia SOM de Honolulu se produjera el consenso requerido. Esta situación se mantuvo hasta la Reunión Ministerial de Seattle, a pesar de los esfuerzos chilenos frente a Australia,

$\overline{32}$ Ch. Signorio, op. cit., y El Mercurio, 26 de octubre 1993, citado por la autora. 
país que recibió al Presidente Aylwin en visita oficial a comienzos de octubre. Dicha visita fue seguida el 18 de octubre por una carta del Presidente Aylwin al Primer Ministro Keating, en la que reiteraba la postura chilena e invocaba las coincidencias entre los gobiernos en las relaciones económicas internacionales y específicamente en lo concerniente a la liberalización de los intercambios en el Pacífico. Una gestión similar se había hecho el 11 de octubre ante el Presidente Clinton, solicitándole la favorable y decisiva disposición de su país que haga posible el cónsenso al respecto. ${ }^{33}$ En esos días se aprovechó también la visita oficial del Presidente mexicano, Carlos Salinas de Gortari, para expresar la conveniencia que Chile y México pudieran acceder como miémbró plenos a la organización de Cooperación Económica de Asia-Pacifico. En noviembre prosiguió el esfuerzo arite Washington, a través de gestiones del Ministro Foxley con los Secretarios de Estado, del "Tesoro," de Comercio, US Trade Representative y Asesor de Seguridad Nacional de la Casa Blanca. ${ }^{34}$

El proceso culminó en Seattle a través de una fórmula de transacción entre la postura favorable a Chile de Malasia, representada principalmente por la influyente y polémica Ministra de Comercio Rafidah Aziz, la voluntad norteamericana y canadiense de allanar el ingreso a México, y las prevénciones australianas sobre la ampliación de APEC: se admitió inmediatamente a México y Papua Nueva Guinea, dejándose acordado el ingreso de Chile para la próxima reunión ministerial, sin perjuicio de la pronta incorporación a los grupos de trabajo, y de una moratoria de tres años a la consideración de nuevos miembros.

La representación chilena, a cargo del embajador Errázuriz, obtuvo a través de numerosas gestionés ante las delegaciones que el comunicado de Seattle se refiriera a un acuerdo existente, sin dejar pendiente el tema del consenso acerca de la participación chilena para la reunión de 1994 en Indonesia. El precio de un año de espera para esta vía de incorporación formal parecia bastante pequeño una vez que se habia asegurado este resultado. El logro diplomático alcanzado fue una recompensa para la visión regional desarrollada en los años anteriores y para la tenacidad de la diplomacia chilena empeñada en concretar esta visión frente a los miembros de APEC. Desde el punto de vista interno, cabría agregar que el ingreso a APEC fue igualmente significativo, por cuanto el gobierno del Presidente Aylwin se encontraba a solamente cuatro meses del

${ }^{33}$ Op. cit, p. 16.

${ }^{34}$ Op. cit., p. 16, nota 28 . 
término de su mandato, de manera que la incorporación al foro económico intergubernamental correspondería necesariamente a las nuevas autoridades.

Entre la histórica reunión de Seattle y la incorporación formal de Chile en la Reunión Ministerial de Jakarta y la II Cumbre de Líderes Económicos de APEC, la estrategia multilateral apuntó a dar credibilidad a la participación chilena en los grupos de trabajo de APEC. Este esfuerzo se concentró en las reuniones de altos funcionarios (Senior Officials Meeting, SOM) y en el Comité de Comercio e Inversiones (CTI). Estas instancias en principio estaban excluidas de la incorporación anticipada de Chile, pero se abrieron gracias a los buenos oficios de algunos gobiernos del grupo ASEAN.

Pero el desafío más complejo se debió a que el rápido crecimiento de los grupos, comités, foros y conferencias de APEC y sus respectivas agendas temáticas (comprendiendo desde la pesca y el turismo hasta la pequeña y mediana empresa y las aduanas, etc.), implicó una labor de socialización y reclutamiento y coordinación de funcionarios en los más variados segmentos de la administración pública, los que por lo general no se encontraban preparados para asumir responsabilidades en APEC. La tarea fue asumida por la nueva Unidad PECC-APEC en la Dirección Económica de la Cancilleria, a cargo de la economista Cristina Bitar, quien se había desempeñado anteriormente en Hacienda junto a Juan Salazar. Desde la jefatura de DIRECON, Salazar apoyó decididamente la gestión del grupo PECC-APEC, que contó con un un pequeño equipo de funcionarios con experiencia en temas de Asia-Pacifico. Este grupo debió vencer grandes dificultades para lanzar la participación en las instancias de trabajo de APEC, principalmente la escasa elaboración existente sobre los temas sustantivos y las políticas a seguir, la poca disponibilidad de funcionarios preparados para integrar las delegaciones y comunicarse efectivamente en inglés, y la falta de recursos ministeriales para financiar los costos de la participación de un creciente calendario de compromisos internacionales. Sin embargo, en el curso del año 1994 la curva de la presencia chilena -básicamente una experiencia de aprendizaje en APEC- fue claramente ascendente, lo que se debió a la capacidad de liderazgo demostrada por DIRECON y la unidad PECC-APEC en el terna, al apoyo ministerial en la propia Cancillería, en Economía y otros ministerios, y al compromiso asumido a nivel presidencial para la Reunión de Lideres Económicos en Bogor, Indonesia, en noviembre de 1994. 
En las circunstancias descritas, era conveniente -como se señaló anteriormente- que lá agenda PECC tuviera un manejo autónomo, aunque crecientemente coordinado con los asuntos APEC y reforzando a DIRECON en este campo a través de los aportes privados y académicos. Este criterio llevó, como se ha visto anteriormente, al establecimiento de la Fundación Chilena del Pacífico, entidad que se haría cargo de CHILPEC, integrando a este Comité a personeros representativos del gobierno, del mundo empresarial y de las principales instituciones académicas calificadas en los temas de Asia-Pacífico. Esta composición permitiría en la práctica a la Fundación cumplir funciones consultivas y de difusión en relación con la agenda APEC. La designación de esta entidad mixta como Centro de Estudios APEC de Chile tuvo lugar en Jos primeros meses de 1995. De esta manera el gobierno cumplió un acuerdo adoptado en Seattle (o sea, antes de su incorporación formal a APEC) sin necesidad de crear una institución ad hoc alternativa de alto costo ni de arbitrar entre las legítimas y previsibles pretensiones que habrían manififestado las instituciones académicas universitarias e independientes con trayectoria e interes legítimo en los temas del Pacífico. Los objetivos del centro de Estudios APEC jon tanto de investigación como especialmente de difusión del conocimiento acerca del proceso de cooperación en la región, y se cumplen a través de un consorcio informal de instituciones participantes.

En 1996, el gobierno siguió un criterio similar en el ámbito empresarial, al encargar a la Fundación apoyar el funcionamiento de la sección nacional del APEC Business Advisory Council (ABAC). Este comité empresarial de $\mathrm{APEC}$, compuesto por tres representantes de alto nivel del empresariado en cada economía, debe presentar a los líderes de APEC en sus cumbres anuales los puntos de vista del sector privado sobre el proceso de liberalización del comercio y las inversiones. De esta manera se pretende iniciar un diálogo entre los gobiernos y los empresarios en APEC, tendiente a potenciar y dar caracteristicas prácticas y tangibles a la cooperación económica. El primer informe de ABAC fue presentado a los Líderes Económicos de APEC (Jefes de Estado y de Gobierno) en la cumbre de Manila. La presencia empresarial se hizo notar especialmente en Manila, por voluntad de los anfitriones filipinos. El principal logro chileno en el ámbito de ABAC en 1996 fue 
la resolución de $A B A C$ de celebrar su tercera sesión ordinaria de 1997 en Santiago, en los días inmediatamente anteriores a PECC XП. ${ }^{35}$

\section{Conclusiones.}

La estrategia multilateral en el Pacifico constituye un elemento innovador en la politica exterior chilena. A partir de comienzos modestos y de una agenda poco diferenciada de los asuntos marítimos y de las relaciones con el Pacífico insular, la estrategia multilateral asume gradualmente mayores dimensiones al concentrarse en los intereses económicos y dirigirse prioritariamente hacia el área del Asia-Pacifico y sus organismos de cooperación.

Esta vasta tarea se emprende de manera pragmática y suprapartidista, o al menos extrapartidista, y con crecientes -aunque todavia imperfectos- esfuerzos de coordinación entre los sectores públiço, empresarial y académico. De esta manera, se procura responder de manera cada vez más informada y eficaz a los grandes desafíos de la participación chilena en los foros PBEC, PECC y APEC, los cuales, sin perjuicio de sus caracteristicas especificas, se perfilan como.circuitos multilaterales complementarios para la implementación : de: una política nacional integrada.

En este estudio no hemos entrado en los detalles sustantivos de la politica chilena en APEC después de Bogor, tarea que excede los objetivos que nos hemos planteado. En todo caso, es posible sefialar que Chile ha logrado perfilarse como una economía que se cuenta entre las más abiertas de APEC, y que tiene tanto la voluntad como la capacidad política, institucional y económica de profundizar su liberalización a través del mecanismo del unilateralismo concertado. Este mecanismo, si bien difiere profundamente de la práctica establecida en el país en materia de negociaciones internacionales, parece manejable en la medida que se percibe como un esquema más flexible que el quid pro quo

\footnotetext{
${ }_{35}$ Los integrantes de $\mathrm{ABAC}$ fueron designados a mediados de 1996 luego de un proceso de consultas entre DIRECON y la Fundación. Fueron nombrados los senores Roberto de Andraca (Vicepresidente de la Fundación), Mario Andrade (Presidente del Capitulo Chileno PBEC y miembro del Directorio de la Fundación) y Félix Bacigalupo. En 1997, Glen Trebilcozk, gerente general de Invercap S.A., reemplazó al primero de los nombrados, y Juan Salazar, actualmente en el sector privado, a Bacigalupo, quien pasó a la calidad de suplente. Enrique Subercaseaux presta apoyo técnico a la Fundación y a los miembros de ABAC desde la secretarja PECC en Singapur, participando en las reuniones ABAC como staffer chileno. Ver APEC Business Advisory Council, APEC Means Business-Bullding Prosperity for our Community, (Singapur: APEC Secretariat, 1996).
} 
tradicional en el ámbito de las negociaciones comerciales multilaterales, y que constituye una reedición modificada, debido a las nuevas circunstancias internas y del contexto internacional, del unilateralismo practicado por Chile en décadas anteriores. Bajo esta perspectiva, Chile presentó en Osaka (noviembre 1995) una serie de compromisos iniciales (el llamado down payment), y ha anunciado su voluntad de completar su programa de liberalización hacia el año 2010, correspondiente al calendario de las economías avanzadas, en vez del 2020 , en que deberían cumplir sus programas las economías en desarrollo. En noviembre de 1996, el gobierno reiteró y puntualizó sus compromisos en la reunión APEC de Manila. ${ }^{36}$

Creemos que el tema de las relaciones entre la política en APEC y otros acuerdos regionales y subregionales -la inserción múltiple de Chile en diferentes regionalismos- debe examinarse por separado. No obstante, nos parece oportuno señalar que la suscripción de un acuerdo de libre comercio entre Chile y el MERCOSUR en junio de 1996 tiene el potencial de fortalecer la participación chilena en APEC, al abrir un espacio económico ampliado a las relaciones entre Chile y Asia-Pacífico, aspecto central de la propuesta de hacer del pais un puente interregional. Frente a este eventual complementación entre la política en Asia-Pacífico y la asociación en MERCOSUR, creemos que el riesgo de desviación de comercio a través de las preferencias subregionales no debería ser de importancia, toda vez que el gobierno anunció su voluntad de seguir bajando el arancel general de importación. ${ }^{37}$

Sin embargo, a pesar de sus notables avances, todavía es largo el camino que debe recorrer el multilateralismo chileno en el Pacífico, en la medida que la información y los medios disponibles son escasos frente a tareas de enorme magnitud, en las que no es posible ignorar las interrelaciones entre política exterior económica, factores políticos, culturales y geográficos. Hacia el futuro, se abren interrogantes de gran magnitud, sobre todo para un actor relativamente pequeño, como Chile, cuya influencia en APEC es necesariamente limitada, pero que está cada vez más vinculado con las economias integrantes de este foro. Entre los posibles escenarios es necesario considerar que el unilateralismo concertado podria estancarse debido a las importantes diferencias bilaterales prevalecientes entre los grandes actores centrales de APEC.

\footnotetext{
${ }^{36}$ Sobre APEC en 1996, ver Hadi Soesastro, "APEC post Osaka", Jakarta ,CSIS, marzo 1996; y Bijit Boira y Mari Pangestu (eds.), Priority Issues in trade and Imestment Liberalisation: Implications for the Asia Pacific Region, (Sirigapur: PECC, 1996).

${ }^{37}$ Proyectanios tratar este tema en un próximo trabajo.
} 
M. Wilhelmy - R.M. Lazo / La política multilateral de Chile ...

Ello podría renovar las presiones para la concertación de acuerdos subregionales de libre comercio entre diversos subconjuntos económicos de la Cuenca del Pacífico. A su vez, Chile no ha descartado este tipo de acuerdos dentro de su política exterior económica, dentro y fuera del ámbito del Pacifico. Una opción de este tipo inevitablemente repercutiría en la participación chilena en APEC.

Con todo, los progresos alcanzados en los últimos ańos parecen promisorios y siguen representando el esfuerzo más avanzado de vinculación nacional con Asia-Pacífico que se ha realizado en América Latina. 